\title{
基层畜牧兽医动物防疫工作重点及开展对策
}

索南措

黄南州动物疫病预防控制中心

DOI:10.32629/ems.v2i4.1607

[摘要] 随着我国经济水平的不断增强, 在畜牧行业也有所提升, 有关企业对于基层畜牧兽医开展工作的要求也不 断的升高。根据目前的发展, 基层畜牧兽医在开展动物防疫工作时,要保证工作的质量,提升动物防疫水平,促进畜牧 业健康、可持续发展。但是在开展工作的过程中还是会出现许多问题,我们要对这些问题进行探讨,并提出解决措施。 [关键词] 基层; 畜牧兽医;动物防疫;工作重点;对策

中图分类号: S8 文献标识码: A

对我国农业的发展来说, 畜牧行业是必不可少的, 因为农业经济的发展, 畜牧行业产生的影响也有所提 升。基层畜牧兽医开展动物防疫工作, 可以有效的减少 动物出现疾病的情况, 而且在动物生病时可以进行有 效的控制。目前, 基层畜牧兽医动物防疫工作中出现的 问题对动物制品的质量产生了严重的影响, 所以, 我们 需要提高动物防疫工作的重视程度。

\section{1 基层畜牧兽医动物防疫工作的现状}

在开展基层畜牧兽医动物防疫工作时, 虽然已经 有了一定的效果，但是在这个过程中仍然存在一些问 题。首先, 在开展基层畜牧兽医动物防疫工作时, 没有 给予足够的重视程度, 在动物接种疫苗的时候也是只 做表面功夫, 没有结合动物实际的发展情况; 其次, 基 层畜牧区存在很多的养殖户，他们缺乏对于动物防疫 工作的认知, 致使动物防疫工作落不到实处, 更是难以 进行发展; 最后, 在开展基层畜牧兽医动物防疫工作的 时候, 没有合理的流程, 在控制动物疫情的时候, 凸显 不出防疫工作的重要性, 致使疫情蔓延, 畜牧区整体的 发展受到约束 ${ }^{[1]}$ 。

\section{2 动物防疫工作的重点内容}

\section{1 动物疫情监测}

在开展基层畜牧兽医动物防疫工作的时候, 最重 要的一点就是要对辖区范围内的养殖户进行动物疫病 监测。只有控制动物疫情确保在合理的范围内, 才能为 养殖效益的提升、动物的健康成长奠定基础。身为基层 畜牧兽医, 在开展防疫工作的时候, 应该针对不同的养 殖户提出专业的防控方案, 使疫病流行的概率得到降 低, 对疫病的传播进行控制。在养殖场发生动物疫病的 情况后, 要及时的采取相关的措施, 将生病的动物隔离 起来, 并且严格的进行消毒工作, 为动物的健康提供保 障。除此之外, 身为基层畜牧兽医, 还需要对辖区内的 动物产生疫病的情况进行调查和记录, 掌握当地疫病 流行的情况, 并且对当时采取的治疗方案以及使用的
预防措施进行全面的总结, 为养殖户在防疫方面做出针 对性的方案, 在接种疫苗的时候, 科学合理进行接种, 防 止该种疫病再次出现在养殖场内。

\section{2 基础设施建设}

对于基层地区来说, 其各项基础设施的建设以及充 分的资金投人,是动物防疫工作可以顺利开展, 并且具有 很高效率的前提保障。基层畜牧兽医站在开展工作的时 候需要向上级部门积极的申请资金, 强化资金帮扶和政 策支持, 建设完善的基础动物防疫设备, 为诊断动物疫 病、防控疫情提供良好的工作环境以及专业化的设施设 备, 方便畜牧兽医工作人员可以针对性的开展防控工作。 但是, 从目前对基层兽医站的调查来说, 在配置基础设施 这个方面, 设施配备不到位的情况还存在、相应的设备老 旧、没有投人高科技的设备, 从工作方面来说, 工作的环 境比较恶略、工作范围比较广、具有很大的工作压力 ${ }^{[2]}$ 。因 为在基层地区, 畜牧兽医工作人员还是比较缺乏的, 在进 行动物防疫工作时, 会经常出现力不从心、不到位的问 题, 促使整个地区在开展动物防疫工作时, 难度比较大。 虽然部分兽医站配备了相应的设施设备, 但是由于没有 专业的人员和管理方面的问题, 导致这些设备没有发挥 出最大的功效, 不利于防疫工作的顺利开展。

\section{3 提升兽医专业水平}

在基层畜牧养殖产业进行现代化发展的过程中,在 开展动物疫病防治、动物疫病诊断工作时, 需要一批专业 化、高素质的人才。提升动物防治质量以及效率的关键因 素就是专业化的兽医工作人员, 基层地区开展动物防疫 工作质量的高低, 离不开兽医工作人员的工作能力和专 业水平, 这些都会影响防疫工作的质量。因此, 在建设基 层兽医站的时候,需要提升兽医队伍基础知识、专业技能 培训的重视程度, 制定科学、合理、完善的中远期培养人 才计划, 开展多种方式的培训, 对兽医工作人员的技能进 行提升。从我国基层兽医站开展防疫工作的现状来说, 普 遍存在兽医工作人员工作素质不高、专业技能不足的情 
况, 许多基层地区的兽医站, 都会从其他地区借调人员, 并不是专业的兽医人才, 在动物防疫技术以及知识方面 有所缺失, 在上岗工作后也没有进行专业的岗前培训, 导致动物防疫工作的实施受到阻碍。

\section{4 动物检查工作}

在日常进行养殖的时候, 需要兽医工作人员对辖区 内的动物进行全面的检测, 检查动物的健康情况, 检查 它们的抗体是否符合规定, 是否超出了免疫期, 观察是 否存在潜在的疾病, 并对其进行预防, 对于那些检查出 来患病的动物, 要明确其生病的原因, 并且采取相应的 治疗措施, 不得已的情况下, 实施扑杀, 进行无害化处 理。同时, 通过全面的对动物健康状况进行检查, 可以帮 助养殖户制定出合理的免疫方案, 并引导其在购买疫苗 的时候从正规的渠道进行采购, 不要采购三无产品, 对 疫苗要做好存储、稀释和注射的工作。

\section{3 基层畜牧兽医动物防疫工作开展对策}

\section{1 开展兽医工作人员培训}

首先，在对基层畜牧兽医工作人员进行培训的时 候, 需要加强专业技能、基础知识方面的培训, 使其专业 素养可以有所提升, 具有丰富的知识储备, 在学习的过 程中可以对最新的技术进行掌握, 促进基层防疫工作内 容的创新。在工作人员上岗之前, 需要对其进行专业的 培训; 在其开展一段时间的工作后, 需要进行继续教育, 开展在职培训, 对其进行考核, 督促工作人员不断的进 行学习, 学习新的知识和技能。同时, 可以设置一定的激 励政策以及惩罚措施, 让工作人员在开展工作的时候要 始终保持正确的工作态度, 爱岗敬业, 树立正确的工作 思想, 在开展基层畜牧动物防疫工作的时候, 理论结合 实践, 对动物防疫工作的有效性进行提升。在开展工作 的同时,需要不断的对福利政策进行完善, 让专业的人 才愿意留在基层服务,提升他们的幸福感 ${ }^{[3]}$ 。

\section{2 开展养殖户培训}

在对养殖户进行培训的时候需要提升重视的程度, 改变养殖户在动物防疫工作方面传统的、错误的思想观 念, 向他们传递现代化的思想观念, 降低因为错误的养 殖方法而产生的损失。在开展养殖户培训的时候, 可以 使用集中培训的方式,让养殖户可以学习并了解基础的 知识, 指导如何科学的进行养殖, 让他们对动物出现病 情时需要及时的报备兽医站并寻求帮助产生一个基本
的认知。同时, 可以使用组织养殖户进行观摩学习的方 式, 让养殖户知道使用正确的养殖方式、经过科学的喂 养可以带来可观的经济效益, 改变他们的认知观念, 推 动养殖户积极主动的进行动物防疫工作。

\section{3 加大经费投入的力度}

在开展基层畜牧兽医动物防疫工作的时候离不开 国家的经济支持, 想要有效的进行动物防疫工作, 在基 础设施设备建设的时候, 需要引人专业的医疗设施, 因 为动物产生疫情的原因不同, 疫情的种类也有所不同, 针对这种情况, 所需要的药物种类也是比较复杂且繁多 的, 在开展这些工作的时候都需要具有充足的资金。所 以, 在基层畜牧区开展防疫工作的时候国家要加大资金 投入的力度, 为动物防疫工作的顺利开展提供资金保 障, 完善各种基础设施的建设, 准备充足的药物库存, 提 升动物防疫工作的有效性, 对基层畜牧区出现动物病情 蔓延情况进行有效的控制, 降低动物疫情出现的几率 ${ }^{[4]}$ 。

3.4 做好疫苗接种工作

想要顺利的进行动物防疫工作, 需要落实免疫工 作, 在开展防疫工作的过程中, 要确保动物接种疫苗, 保 证辖区范围内的动物有序的进行疫苗接种工作, 定期的 对养殖区进行消毒和清洁工作, 提升动物的免疫力, 防 止出现病毒和细菌传播的情况。另外, 要做好疫苗抽查 工作, 确保注射疫苗工作能有效的落实。

\section{4 结束语}

在基层畜牧兽医开展防疫工作的时候, 需要国家政 策的大力扶持, 加强人才引进和培养的力度, 改变养殖 户传统的养殖观念, 让基层所有人员都了解防疫工作的 重要性, 学习相关的防疫知识, 促进基层畜牧业经济的 发展。

\section{[参考文献]}

[1]宋龙华. 基层畜牧兽医动物防疫工作存在的问题 及对策 [J].乡村科技,2018,(27):62-62.

[2]杨蕾. 对基层畜牧兽医动物防疫工作的重点探讨 [J].今日畜牧兽医, 2018,34(3):47-47.

[3]田超. 对基层畜牧兽医动物防疫工作重点研究 [J].农家科技, 2018, (9):113-113.

[4]杨景华. 基层畜牧兽医动物防疫工作的重点及建 议探讨[J].兽医导刊, 2019,(10):55-55. 